Article

\title{
Experimental Analysis of an Air Heat Pump for Heating Service Using a "Hardware-In-The-Loop" System
}

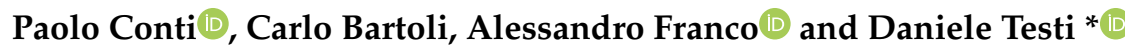 \\ Department of Energy, Systems, Territory, and Constructions Engineering (DESTEC), University of Pisa, \\ Largo Lucio Lazzarino, 56122 Pisa, Italy; paolo.conti@unipi.it (P.C.); carlo.bartoli@unipi.it (C.B.); \\ alessandro.franco@unipi.it (A.F.) \\ * Correspondence: daniele.testi@unipi.it
}

Received: 10 July 2020; Accepted: 18 August 2020; Published: 1 September 2020

check for updates

\begin{abstract}
Estimating and optimizing the dynamic performance of a heat pump system coupled to a building is a paramount yet complex task, especially under intermittent conditions. This paper presents the "hardware-in-the-loop" experimental campaign of an air-source heat pump serving a typical dwelling in Pisa (Italy). The experimental apparatus uses real pieces of equipment, together with a thermal load emulator controlled by a full energy dynamic simulation of the considered building. Real weather data are continuously collected and used to run the simulation. The experimental campaign was performed from November 2019 to February 2020, measuring the system performances under real climate and load dynamics. With a water set point equal to $40^{\circ} \mathrm{C}$, the average heat pump coefficient of performance was about 3, while the overall building-plant performance was around 2. The deviation between the two performance indexes can be ascribed to the continuous on-off signals given by the zone thermostat due to the oversized capacity of the heat emission system. The overall performance raised to 2.5 thanks to a smoother operation obtained with reduced supply temperature $\left(35^{\circ} \mathrm{C}\right)$ and fan coil speed. The paper demonstrates the relevance of a dynamic analysis of the building-HVAC system and the potential of the "hardware-in-the-loop" approach in assessing actual part-load heat pump performances with respect to the standard stationary methodology.
\end{abstract}

Keywords: hardware-in-the-loop; heat pumps; dynamic simulation; experimental performances; control strategy; partial loads; on-off cycles; building dynamics; building-heating system coupling

\section{Introduction}

Heat Pump (HP) is a key technology to increase the energy efficiency and the use of renewable energy in civil and residential buildings [1]. With respect to electric or natural-gas boilers, HPs have higher energy conversion efficiency and allow the exploitation of the renewable energy coming from the outdoor source (e.g., external air), together with the renewable share of the electricity production mix. In this regard, heat pumps are recognized to be increasingly important for electrical grids (microand smart-included), as well as for distributed energy systems that aim at even higher renewable energy contribution [1-6]. The fluctuating and stochastic production of renewables represents a critical issue to ensure the balance between power production and load: HPs may mitigate this drawback by shifting a given share of the thermal energy demand to the electrical one [5,6]. A proper cooperation among HPs, back-up generators and energy storages may additionally increase the flexibility of the overall energy system $[4,7]$. Demand response techniques are also possible [8,9].

Several scientific and technological issues in the field of HP systems are still unsolved. One of those is the problem of the efficiency reduction under dynamic operating conditions [10]. Especially in 
mild climates conditions and during intermediate seasons, the actual thermal load profile results are notably lower than the design capacity and intermittent operation occurs. The frequent on-off cycles and the resulting dynamic regime for the whole HP system determine a considerable reduction in the mean (or seasonal) Coefficient of Performance (SCOP): while in nominal operating conditions the SCOP ranges from values of 3 (in cooling mode) to 4 (in heating mode), in intermittent operation the values are often reduced even below the values of 2 and $3[1,11]$.

The development of sizing and management strategies is fundamental to improve the actual performances of HP-based systems and guarantee low energy consumption, reduced operating costs, and high comfort levels for occupants. From this perspective, some works based on the dynamic simulation of the Heating and Ventilation Air Conditioning (HVAC)-building system have been proposed in the literature $[6,12]$. However, the results obtained through a simulation approach would always be followed by some experimental tests in order to validate assumptions, subsystems models, dynamics timescales, and estimated operative performances [13-15]; otherwise, results can be affected by notable errors or correspond to impracticable control actions to be realized in a real system [1].

Full experimental campaigns are often unfeasible for building energy systems, due to the long time required, technical and economical efforts. Then, the use of "hardware-in-the-loop" (HiL) systems is a convenient experimental approach that is quite novel for these applications. In other fields, such as automotive and aerospace industries, HiL tests are standard practice and currently their importance is even increasing, due to the onset of advanced driver assistance and automated driving [16]. In the case of building energy systems, with the HiL approach, the experimental campaign is performed in a laboratory environment through an apparatus made of real thermal generators, heat storages and/or any other pieces of equipment, while the real building is replaced by a thermal load emulator controlled by a full energy dynamic simulation $[15,17-19]$. Other technical units may also be substituted by appropriate emulators, to be integrated with the energy system. Using real weather data, the tested devices (e.g., the heat pump) experience the same working conditions and load profiles that they would experience in a real application $[9,10,13]$. HiL experimentation is also characterized by a great flexibility, because it can test and optimize many different building-HVAC configurations and control strategies $[17,20,21]$.

In this experimental framework, the objective of the present paper is to show the relevance of the dynamic coupling between building and heat pump system in terms of energy performance, especially when frequent on-off cycles occur, and quantitatively assess the deviations from standard methods based on stationary measurements.

The conceptual layout of the building emulator and thermo-hydraulic HiL experimental system available in the laboratories of DESTEC of the University of Pisa, named Building Emulator and Integrated Energy System (BE-IES), is shown in Figure 1, including all the installed devices, measurements, controls, and corresponding energy fluxes.

Following a thorough description of the BE-IES laboratory components and management options, the results of an experimental campaign concerning the dynamic operation of an air-source HP serving a typical apartment located in Pisa in wintertime are presented and analyzed. In particular, the paper focuses on the effects of the supply temperature to the heat emission system and the resulting on-off signal provided by the typical zone thermostats located inside the building.

Experimental performances are compared with the estimated ones according to current widespread methodologies based on the interpolation of manufacturers' experimental data [22-24]. These methods can be classified as "quasi-stationary", as they are based on a sequence of steady-state working conditions; the effects of dynamic phenomena (e.g., on-off cycles) are evaluated through empirical penalization factors. However, these inefficiencies can be relevant and hard to model with simplified correlations as they depend on specific load profile, heating loop characteristics, HVAC-building interconnected dynamics; therefore, the application of standardized methodologies can lead to wrong estimations of the system efficiency and related economic viability. 


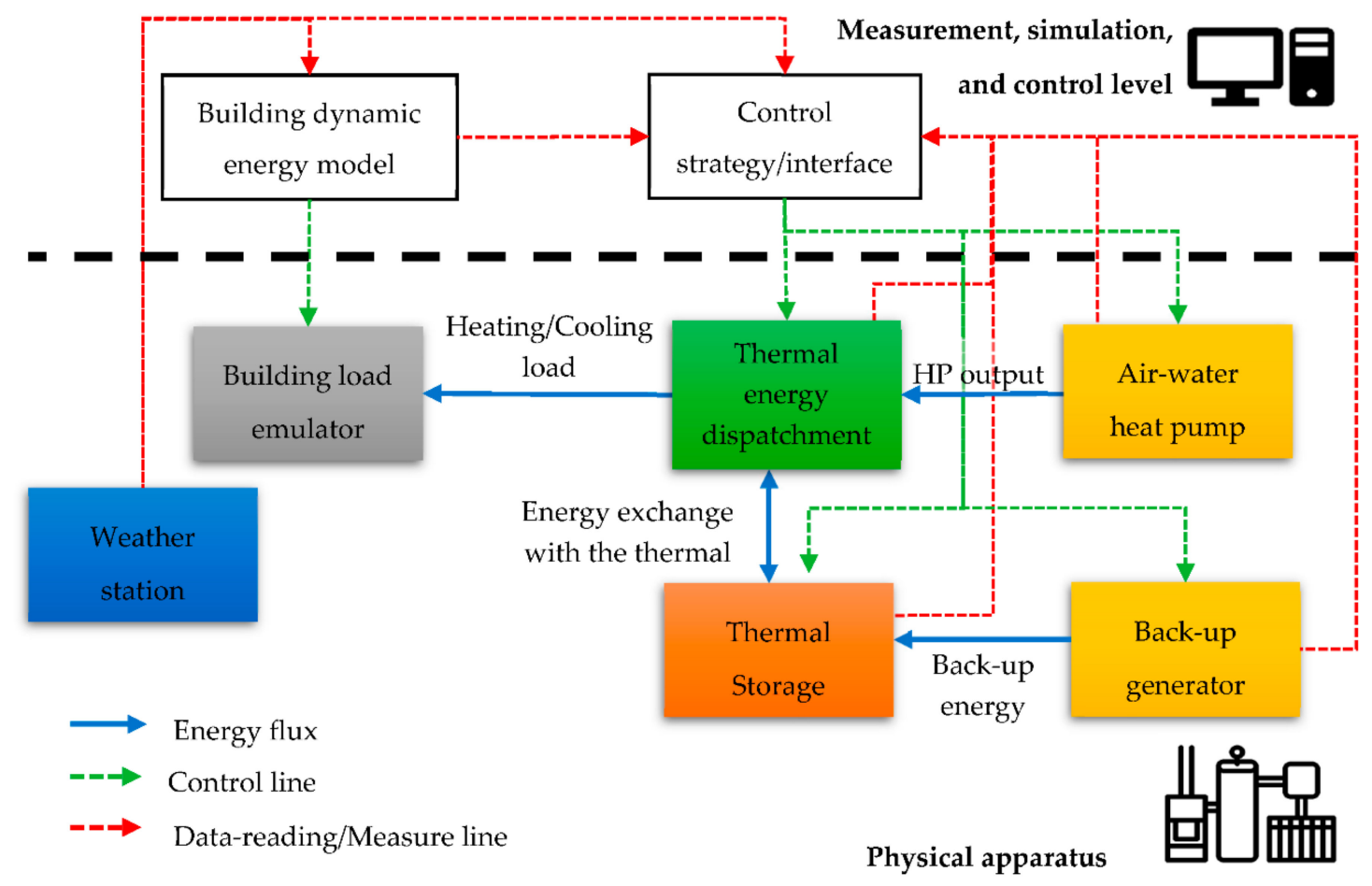

Figure 1. Components and logical scheme of the building emulator and integrated energy system (BE-IES) "hardware-in-the-loop" apparatus.

The rest of the paper is structured as follows: Section 2 describes the BE-IES experimental apparatus and the operational strategy of the HiL system; Section 3 presents the dynamic energy model of the building and heat emission system that control the building emulator; Section 4 presents the case study and the three tested operational strategies. Finally, Section 5 discusses the experimental data, the actual coefficient of performances of the building-HVAC system with respect to the corresponding ones evaluated through state-of-the-art technical standards (briefly recapped in Appendix A), and analyzes the causes of the thermal inefficiencies connected with the operation of the heat pump and the overall HVAC system, leading to the conclusions of Section 6.

\section{Description of the "Hardware-In-The-Loop" Apparatus}

The experimental apparatus is made of several thermal and electrical devices: some of them are real HVAC piece of equipment, others act as emulators (e.g., the building). The apparatus sizing was tailored to the typical design thermal load of single-family houses, namely some $\mathrm{kW}$.

\subsection{Equipment Description and Layout}

The list of components and the overall layout of the experimental apparatus are shown in Table 1 and Figure 2, respectively. The system has separate generation and user sections, connected by the main heat exchanger (mHEx). The building emulator (BE), the mHEx and the thermal storage (TS) are connected through two three-way control valves that link two devices at a time, according to the signal received by the main monitoring and control (M\&C) system. The apparatus can thus operate in three possible configurations:

(a) AHP-TS: the heat pump heats up the thermal storage;

(b) mHEx-BE: the heat pump is directly connected to the building thermal load;

(c) TS-BE: the building thermal load is met by the thermal storage. 
The water content of the primary loop corresponds to a typical volume of a single-family heating system, namely around $45 \mathrm{~L}$. This can also test the effects of the water loop dynamics in a real system. The volume also includes the expansion vessel and the inertial storage required by the AHP (about $7 \mathrm{~L} / \mathrm{kW}$ ).

The BE consists of an oversized outdoor heat exchanger controlled by a three-way mixing valve. The emulator produces a fluid enthalpy variation equal to the thermal power evaluated by the dynamic simulation of the simulated building (see Section 3). The outdoor air-water heat exchanger has an oversized nominal capacity with respect to the rest of HiL apparatus to ensure the heat transfer when the outdoor air and the secondary loop have a close temperature.

The thermal storage $(520 \mathrm{~L}$ ) is connected to the user loop and can be used to provide thermal energy to the BE in replacement of the AHP. The system does not exploit the bulk fluid that is intended to be used for domestic hot water purposes. The energy transfer occurs through an oversized internal coil. The electrical resistance $(4.8 \mathrm{~kW})$ is the standard TS electrical back-up, however, it can also be controlled to deliver a given profile of thermal power, thus acting as an emulator of other generation technologies.

Table 1. Components of the BE-IES “Hardware-in-the-Loop” Apparatus.

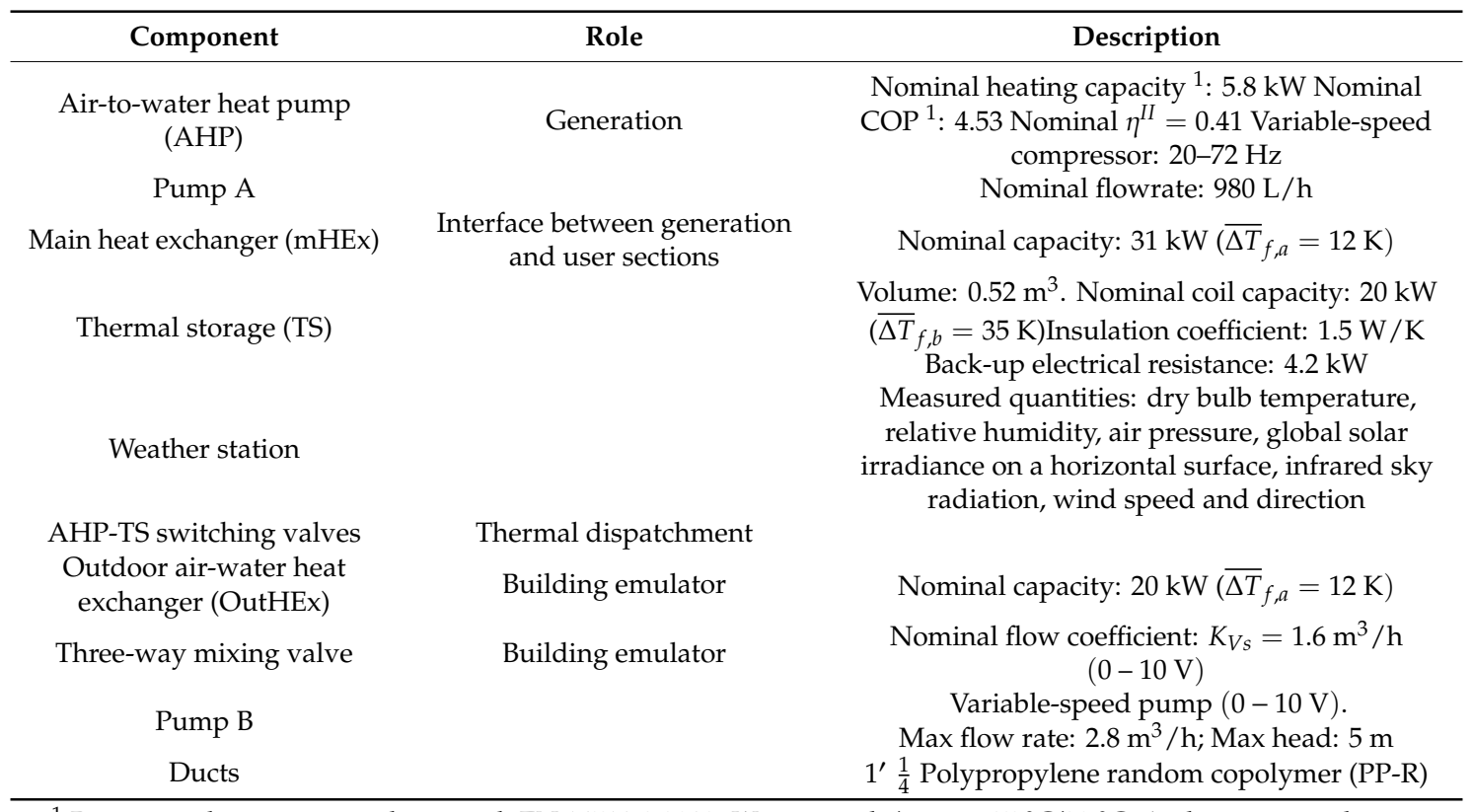

${ }^{1}$ Rating conditions in accordance with EN 14511-2:2018: Water supply/return: $35^{\circ} \mathrm{C} / 30{ }^{\circ} \mathrm{C}$; Ambient air conditions: $7^{\circ} \mathrm{C}$ DBT $/ 6^{\circ} \mathrm{C}$ WBT.

Building emulator

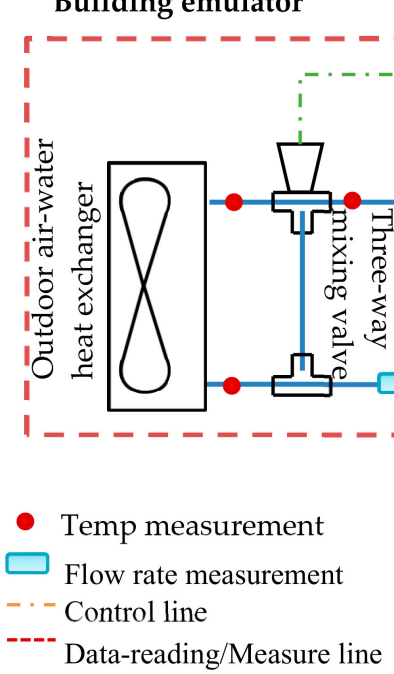

Monitoring and control system

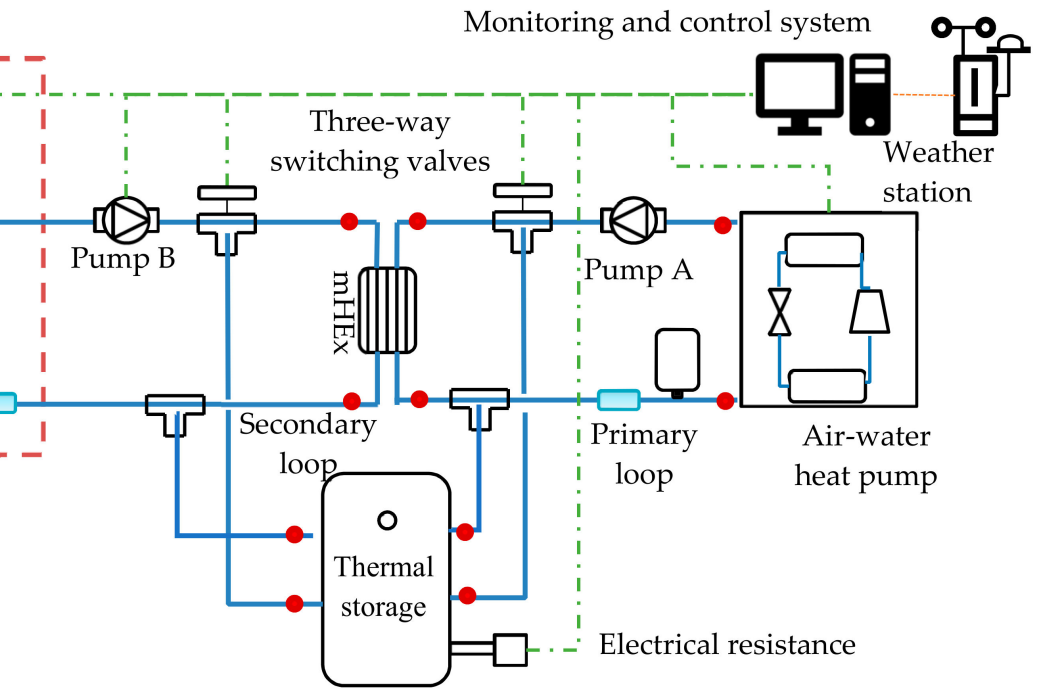

Figure 2. Layout and components of the BE-IES “hardware-in-the-loop" apparatus. 


\subsection{Measurement System}

The HiL apparatus is equipped with industrial measurement devices with the typical performances of such technologies. The choice of not using accurate laboratory equipment is motivated by the will to develop control strategies that can be performed by commercial HVAC devices and their typical monitoring, control, and actuator systems.

The temperature is read by eleven Negative Temperature Coefficient (NTC) thermistors, located as in Figure 2. NTC thermistors were chosen because of their high accuracy in the operational temperature range of the HiL apparatus, together with their ease of installation with respect to other types of sensors (e.g., thermocouples). All the NTC were calibrated before being installed in the apparatus. The accuracy of each thermistor in the $-5 \div 50{ }^{\circ} \mathrm{C}$ range was evaluated as equal to $\pm 0.20 \mathrm{~K}$ (confidence level of $95.4 \%$, i.e., $2 \sigma$ ). The corresponding accuracy on a temperature drop measure was $\pm 0.3 \mathrm{~K}$. For fluid measurements, the NTC thermistors were stuck inside a copper probe located in approximately the middle of the flow.

The flow rate in the two loops was measured through two industrial Kármán vortex flowmeters, located as in Figure 2. The calibration procedure revealed an overall accuracy in the $5 \div 25 \mathrm{~L} / \mathrm{m}$ range of $\pm 0.0225 \mathrm{~L} / \mathrm{m}$ (confidence level of $95.4 \%$, i.e., $2 \sigma$ ).

The resulting accuracy on the enthalpy drop measures, namely the thermal power, was evaluated through the error propagation theory. For instance, the accuracy in proximity of the nominal AHP flow rate $(980 \mathrm{~L} / \mathrm{h})$ and temperature drop $(5 \mathrm{~K})$ of the AHP is about $320 \mathrm{~W}$, which corresponds to a relative error of about $5.52 \%$ with respect to the nominal capacity $(5.800 \mathrm{~kW})$.

The weather station is located on the roof of the laboratory building. The accuracy of each sensor is shown in Table 2.

Table 2. Accuracy of the Weather Station Instruments.

\begin{tabular}{ccc}
\hline Sensor & Measured Quantity & Accuracy \\
\hline $\begin{array}{c}\text { Thermistor } \\
\text { (PT 100) }\end{array}$ & Dry bulb temperature $\left({ }^{\circ} \mathrm{C}\right)$ & $\pm 0.15 \mathrm{~K} \pm 0.1 \%$ \\
$\begin{array}{c}\text { Metal oxide's electrical capacity } \\
\text { Piezoresistive pressure sensors }\end{array}$ & Relative humidity $(0-1)$ & $\pm 0.015 \pm 1.5 \%$ \\
$\pm 50 \mathrm{~Pa}$ & $\pm 1^{\circ}($ direction) \\
Ultrasonic anemometer & Air pressure $(\mathrm{Pa})$ & $\pm 0.2 \mathrm{~m} / \mathrm{s} \pm 2 \% \mathrm{readings}(\mathrm{speed})$ \\
Thermopile Pyranometer & Direction and speed & $\pm 10 \%$ \\
Thermopile Pyrgeometer & $\begin{array}{c}\text { Global solar irradiance }\left(\mathrm{W} / \mathrm{m}^{2}\right) \text { in the } \\
\text { wavelength range } 0.30 \div 2.80 \mu \mathrm{m}\end{array}$ & $\pm 10 \%$ \\
\hline
\end{tabular}

\subsection{Monitoring and Control System: Operational Strategy of the HiL Apparatus}

All the measurements are collected by a desktop computer through some in-house developed LabVIEW $^{\circledR}$ virtual instruments (VIs). The same software is used to run the dynamic simulation of the building and to control the HiL apparatus (i.e., building emulator, valves, and AHP), according to the operational scheme already presented in Figure 1 and hereafter discussed in detail. The dynamic simulation of the building is based on an in-house validated algorithm written in MATLAB ${ }^{\circledR}$ language, corresponding to the thermal network model described in Section 3.

According to the chosen monitoring and simulation time step, the M\&C system collects the weather data, the fluid temperature and the flow rate in the various HiL sections, together with the electrical energy input of AHP and ancillary systems. Then, it uses the actual weather data, the supply temperature to the $\mathrm{BE}$, and the current thermal state of the simulated building to evaluate the performance of the simulated heat emission units (see Section 3). The latter heat output and the actual climate data are thus used to simulate the thermal evolution of the building for the next time step. At the same time, the three-way mixing valve within the $\mathrm{BE}$ is controlled though a Proportional-Integral-Derivative (PID) controller to deliver the simulated thermal performance at the 
mHEx (or in the TS). The procedure is repeated at each time step and emulates the dynamic operation of an actual AHP-TS system connected to the simulated building. Depending on the chosen control strategy, the AHP can be switched off or used to heat-up the thermal storage by controlling the AHP-TS switch valve.

\section{Dynamic Simulation Model of the Building and Heat Emission System}

The experimental analysis based on the HiL system requires an accurate energy model of the building to run the BE. Figure 3 shows the main heat fluxes affecting the energy balance of a generic building or thermal zone that has been included in the building dynamic energy model, namely: heat transfer through opaque and glazed surfaces, ventilation losses, heat gains related to solar radiation, occupants, and electrical appliances. For the sake of clarity, in Figure 3 we do not display the energy stored in building masses, such as external and internal walls. However, these quantities and their effects in the thermal evolution of the building are included in the dynamic energy model.

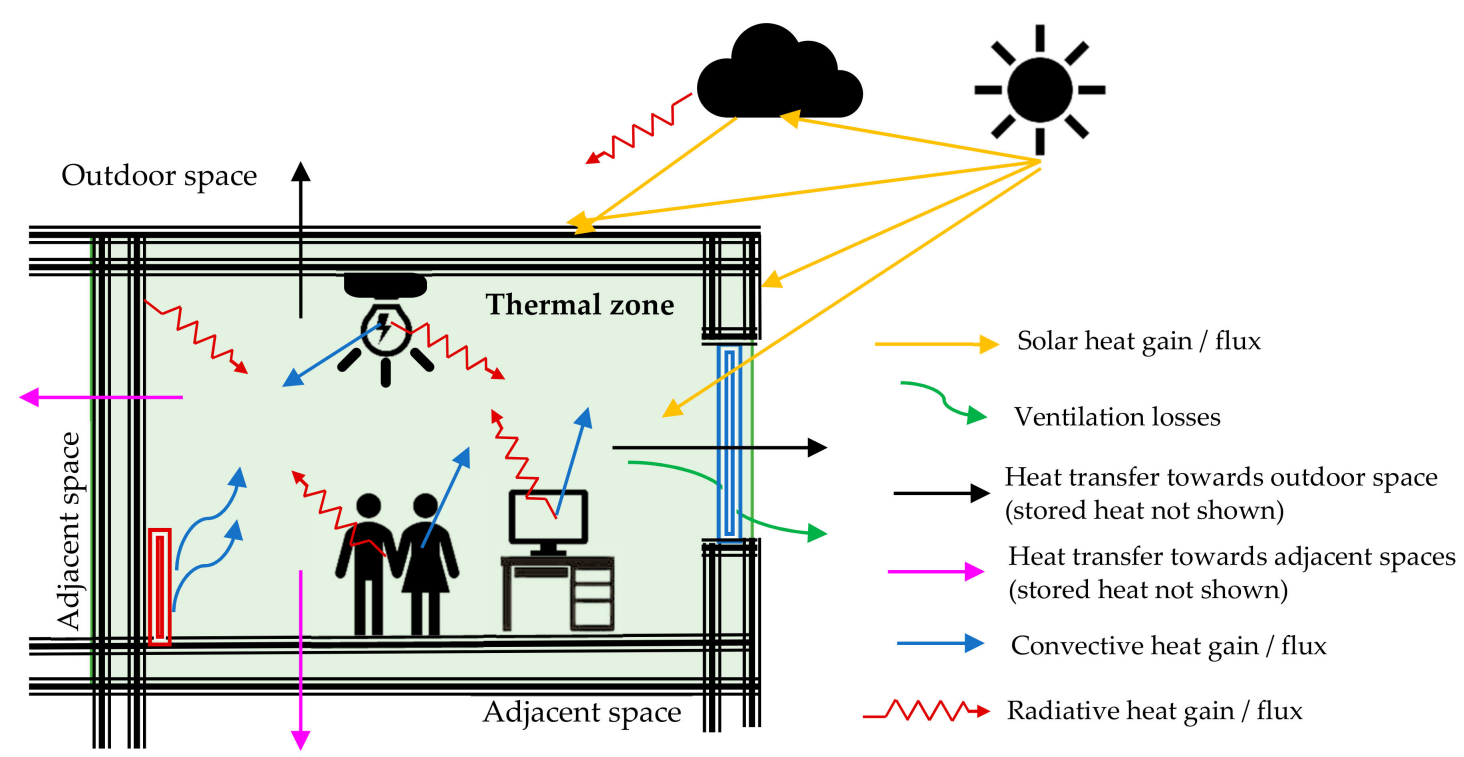

Figure 3. Illustrative scheme of the main energy/heat fluxes affecting the building energy balance (stored energy contributions are not shown).

In this work, we used a classical thermal network approach, widely used at both research and professional levels (see, for instance, EN ISO 52016-1:2017 [25]). The building elements are modeled as electrical nodes connected to each other by equivalent electrical resistances, capacities, time-dependent currents and voltage generators. A summary list of considered phenomena and the corresponding electrical elements can be found in Section 2.1 of [26], including all the info on the thermal-network model and its validation. The building dynamic model corresponds to a $(N \times N)$ linear set of equations that can be quickly solved at each timestep. $N$ is the number of thermal nodes considered in the model, including the one of indoor air.

The evolution of nodes' temperature is a function of climate data (e.g., outdoor air temperature, solar irradiance, sky temperature), heat gains (e.g., people, electrical appliances, and lighting), and heat exchanged by the system terminals. All these elements are modeled as voltage or current generators: their source value is updated at each timestep, according to a given profile (e.g., occupants' presence) or measured quantities in the HiL apparatus (e.g., climate data and supply temperature to the heat emission systems). The heat gain delivered by the emission system can be evaluated through a few additional linear equations to be added to the overall set representing the building. In this work, 
we refer to fan coil units (FCUs) as heat terminal units. The heat transfer performance is modeled through the classical methods of heat exchangers theory, namely

$$
\left\{\begin{array}{c}
\dot{Q}_{F C U}=\dot{m}_{f} \mathcal{C}_{f}\left(T_{f, \text { in }}-T_{f, \text { out }}\right) \\
\dot{Q}_{F C U}=\dot{m}_{a, \text { vel }} c_{a}\left(T_{a, \text { out }}-T_{a, \text { in }}\right) \\
\dot{Q}_{F C U}=(U A)_{\text {vel }} \overline{\Delta T}_{f, a}
\end{array}\right.
$$

The set of Equation (1) allows the evaluation of $\dot{Q}_{F C U}, T_{a, \text { out }}, T_{f, \text { out }}$ as a function of the inlet air temperature, $T_{a, i n}$, inlet fluid temperature, $T_{f, i n}$, air flow rate, $\dot{m}_{a, v e l}$, water flow rate, $\dot{m}_{f}$, and overall heat transfer coefficient $(U A)_{t o t, v e l}$, evaluated from FCU manufacturer's datasheet. The subscript vel indicates that different values of the coefficient are used according to the fan speed (generally, high, medium, and low).

The heating performance of the fan coils and the corresponding heat gain for the indoor air node are evaluated at each timestep. If $\overline{\Delta T}_{f, a}$ is approximated with the difference between the arithmetic means of water and air temperature, the set of Equation (1) is linear and it can be added and solved in conjunction with the overall algebraic model of the building. Otherwise, classical numerical techniques for non-linear set of equations can be used. Shortly, the heat emission system is modelled as two additional thermal nodes, $T_{f, \text { in }}$ and $T_{f, \text { out }}$, in the overall building thermal network. $T_{f, \text { in }}$ is set equal to the measured temperature of the fluid at the inlet section of the BE; $T_{f, o u t}$ is an unknown of the problem to be calculated at each timestep. Its value is then applied as the set point for the three-way mixing vale in the $\mathrm{BE}$.

\section{Description of the Case Study}

The above-described HiL apparatus was used to emulate the seasonal winter performance of a commercial AHP acting as a heat generator in the selected building: a typical single-family house.

\subsection{Reference Boilding and Heat Emission System}

The case study is a typical apartment located at the top floor of a building (see Figure 4), situated in Pisa, Italy. Having a single thermostat set at $20^{\circ} \mathrm{C}$, according to accepted definitions (see, for instance [27]), the whole apartment can be modeled as a single thermal zone, with a total floor area and volume equal to $84 \mathrm{~m}^{2}$ and $227 \mathrm{~m}^{3}$, respectively. The thermal zone has four external walls with double pane windows (N, E, S, and roof); the western wall and the floor are adjacent to similar apartments. The stratigraphy of walls is typical of Italian structures in the 1980s: the external walls are made of two layers of bricks, concrete and plaster for a total width of about $50 \mathrm{~cm}$; the wall at West is similar to the external ones, but the width is reduced to about $30 \mathrm{~cm}$; the internal walls are light elements made of narrow bricks (about $10 \mathrm{~cm}$ ); the external roof is horizontal and entirely practicable, the supporting structures are made of 30-cm slabs reinforced with concrete beams. The roof is not considered to be covered by snow for a significant amount of time (with consequent effects on its heat exchange properties during wintertime), since it very rarely snows in Pisa. The internal walls between rooms are included in the analysis to account for their thermal inertia. The overall transmission coefficients of walls and windows are reported in Table 3. Air change rate has been set as equal to 0.5 volumes per hour. Occupants, lighting, and electrical appliances are included in the building energy balance as heat gains. The corresponding hourly profiles are shown in Figure 5.

This design thermal load of the case study (about $5.7 \mathrm{~kW}$ ) is coherent with the thermal capacity of tested AHP. Considering the number of rooms, the assumed seven equal fan coils located within the thermal zone. The nominal data depending on fan speed are provided by manufacturer's datasheet (see Table 4) according to the rating conditions of EN 1397:2015 [28]. 
Table 3. Geometry and Thermal Characteristics of the Envelope.

\begin{tabular}{cccc}
\hline Wall & Surface $\mathbf{~ m}^{2}$ & Overall Transmittance $\mathbf{W} /\left(\mathbf{m}^{2} \mathbf{K}\right)$ & Weight $\mathbf{k g} / \mathbf{m}^{2}$ \\
\hline Roof & 84 & 0.6 & 485 \\
Northern & 19 & 0.6 & 345 \\
(glazed) & $(2 \times 3.36)$ & 2.8 & 345 \\
Eastern & 32 & 0.6 & \\
(glazed) & $(2 \times 1.96)$ & 2.8 & 345 \\
Southern & 14 & 0.6 & 128 \\
(glazed) & $(4.2)$ & 2.8 & 339 \\
Western & 38 & 1.5 & 120 \\
Floor & 84 & 1.2 & \\
Internal walls & 79 & 1.5 & \\
\hline
\end{tabular}

Total external (opaque-glazed-total): $201-7.5-209 \mathrm{~m}^{2}$

Surface-volume ratio: 0.91

Overall weight of wall per floor area: $1232 \mathrm{~kg} / \mathrm{m}^{2}$

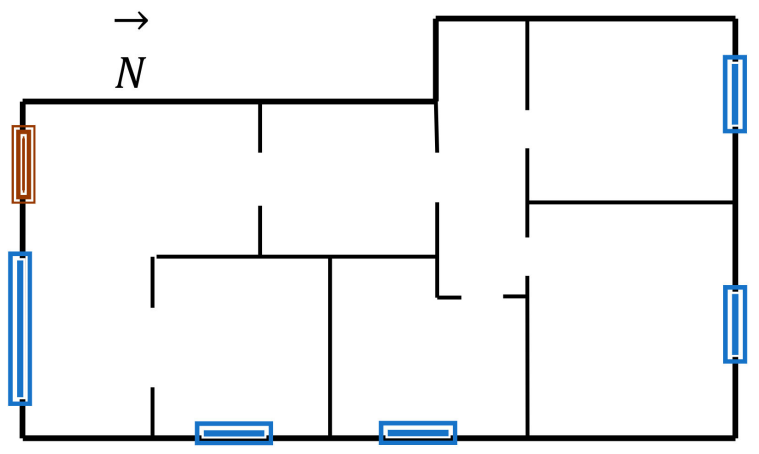

Figure 4. Scheme of the apartment (blue boxes are windows, while the brown box is the main door).

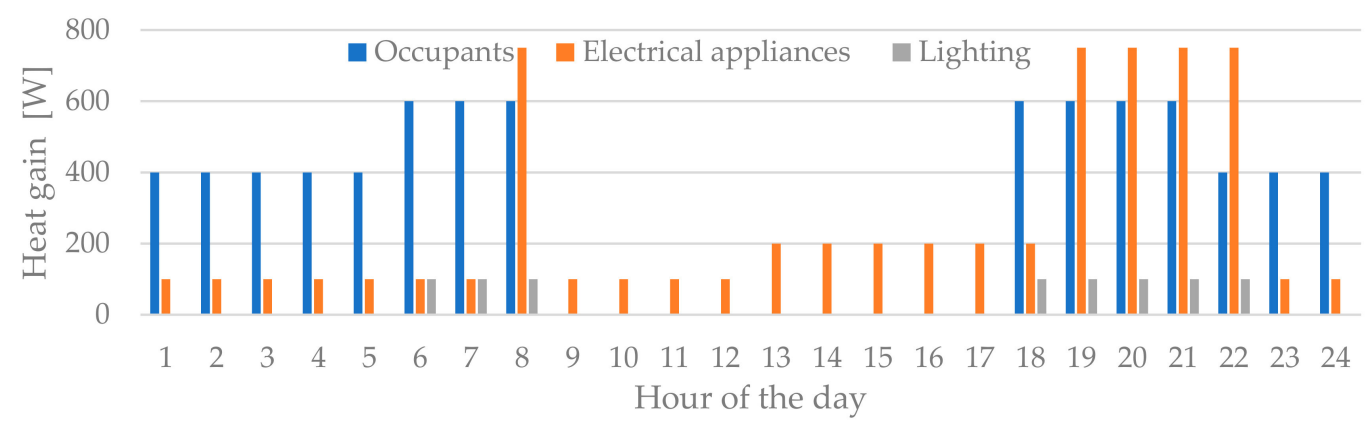

Figure 5. Daily profiles of internal heat gains for the apartment.

Table 4. Fan coil unit (FCU) Manufacturer's Datasheet ${ }^{1}$.

\begin{tabular}{cccc}
\hline & Max & Med & Min \\
\hline Thermal power, $\mathrm{kW}$ & 1.00 & 0.73 & 0.52 \\
Water flow rate, $\mathrm{L} / \mathrm{h}$ & 174 & 126 & 92 \\
Air flow rate, $\mathrm{m}^{3} / \mathrm{h}$ & 180 & 120 & 80 \\
\hline
\end{tabular}

${ }^{1}$ Rating conditions in accordance with EN 1397:2015 [28]: Water supply/return: $45^{\circ} \mathrm{C} / 40{ }^{\circ} \mathrm{C}$; Ambient air conditions: $20^{\circ} \mathrm{C}$ DBT.

\subsection{Test Description and Objectives}

The experimental campaign was performed from November 2019 to February 2020 during the heating period. The main objective was the measurement of the seasonal performances of the AHP and of the whole HVAC-building system in real operational conditions, thus subjected to various on/off 
and modulation cycles because of weather and heat gains evolution, building thermal inertia, water loop and AHP generator dynamic characteristics.

Different simplified, but realistic, AHP control modes were tested. As previously mentioned, a single-zone thermostat controlled the on/off signal to the AHP with an indoor setpoint of $20 \pm 1{ }^{\circ} \mathrm{C}$. Three operational modes of the fan coils were tested in order to evaluate their effect on the system performance: MOD\#1 corresponds to a setpoint value of the supply temperature equal to $40{ }^{\circ} \mathrm{C}$ and MED fan coil speed; MOD\#2 uses the same supply temperature but the fan coil speed was reduced to MIN; MOD\#3 has a supply temperature set equal to $35^{\circ} \mathrm{C}$ and MIN as fan coil speed. The thermal storage was not used in this test campaign as it is not usually present in apartments of multi-apartment buildings with autonomous heating system.

Two seasonal coefficients of performance were chosen as performance indexes to compare the three operational modes: $S C O P_{A H P}$ is defined as the ratio of the thermal energy output and electrical energy input at the AHP devices over a given operational period (see Equation (2)); $S C O P_{\text {sys }}$ is defined as the ratio of the thermal energy delivered to the building emulator (i.e., simulated fan coils) and electrical energy input at the AHP devices over a given operational period (see Equation (3)).

$$
\begin{aligned}
\operatorname{SCOP}_{A H P} & =\frac{\int_{\tau} \dot{m}_{A H P, f} \mathcal{C}_{f}\left(T_{A H P, \text { out }}-T_{A H P, \text { in }}\right) d \tau}{\int_{\tau} \dot{W}_{A H P, \text { in }} d \tau} \\
S C O P_{\text {sys }} & =\frac{\int_{\tau} \dot{m}_{F C U, f} \mathcal{C}_{f}\left(T_{F C U, \text { in }}-T_{F C U, \text { out }}\right) d \tau}{\int_{\tau} \dot{W}_{H P, \text { in }} d \tau}
\end{aligned}
$$

The two performance indexes allow a separate analysis of the heat generator and of the overall building-HVAC system. $S C O P_{s y s}$ only refers to the useful heat delivered to the building thermal zone, thus it can be used to evaluate the relevance of the thermal losses associated to the distribution pipework and to the control of the emulated heating system.

\section{Results}

In this section, we discuss how the system operates under the three control strategies during the whole test period. To better analyze the dynamics of operative quantities, Figures 6-8 show some typical days under MOD\#1, MOD\#2, MOD\#3 in a typical mild (left subfigures) and cold days (right subfigures). The upper subfigures show the profile of the AHP and FCU thermal outputs; the two profiles are zero when the heating system is switched off. The lower subfigures show the evolution of some relevant temperatures, namely, the AHP supply, the AHP return, indoor air, and external air. We note that the AHP manages to maintain the thermal comfort conditions within the apartment (i.e., $T_{i}=20 \pm 1{ }^{\circ} \mathrm{C}$ ) in all the periods, independently from the control mode.

In this work, we compare the experimental performances of the AHP with the ones evaluated through the state-of-the-art methodology for calculation of heat pump energy requirements and efficiency presented in technical standards EN 15316-4-2:2017 [22] and EN 14825:2018 [24]. The method is based on manufacturers' datasheets and represents the main reference for energy dynamic simulations, energy audits, and cost-benefit analysis of heat generation alternatives. The comparison is thus aimed at evaluating the effectiveness of the standard methodology to properly account for the penalization effects due to the operation dynamics. On the other hand, quantitative comparisons with similar works, in which a modulating air-to-water heat pump is monitored when coupled to a HiL system [10] or to an existing building [29,30], or it is fully simulated under dynamic building-coupled conditions [31], are somehow misleading, since energy performances are very heterogeneous, being strongly influenced by climatic conditions and building and heat pump characteristics. However, in these cases, a meaningful parameter for comparison purposes is the penalization factor due to partial loads (see Appendix A). In this regard, the measured performance reduction goes from about $10 \%$ [32-34] to over 30\% [35], depending on the frequency of the on-off cycles. 


\subsection{Analysis of MOD\#1 Operational Strategy: Energy Losses Due to On-Off Cycles}

When MOD\#1 applies $\left(\mathrm{Vel}=\mathrm{MED} ; \mathrm{T}_{\text {out }, A H P}^{*}=40^{\circ} \mathrm{C}\right)$, the profiles are characterized by continuous on-off cycles of about $40 \mathrm{~min}$ (see Figure 6). The average duration of each on period, approx. $20 \mathrm{~min}$, is not sufficient to achieve a steady state condition of the water loop, thus the supply and return temperatures do not reach the setpoint values and continuously fluctuate. However, the FCU thermal output during this transient period is enough to heat up the indoor air until the switching off conditions (i.e., $21^{\circ} \mathrm{C}$ ); the heat pump was thus deactivated without any modulation of the compressor speed. Figure 9 shows the distribution of compressor frequency: when MOD\#1 applies, the frequency was null or about $49 \mathrm{~Hz}$ for more than $80 \%$ of the time. Figure 10 shows the distribution of the duration of the ON periods: when MOD\#1 applies, ON periods of $15-30$ min covered more than $70 \%$ of the total operative time.
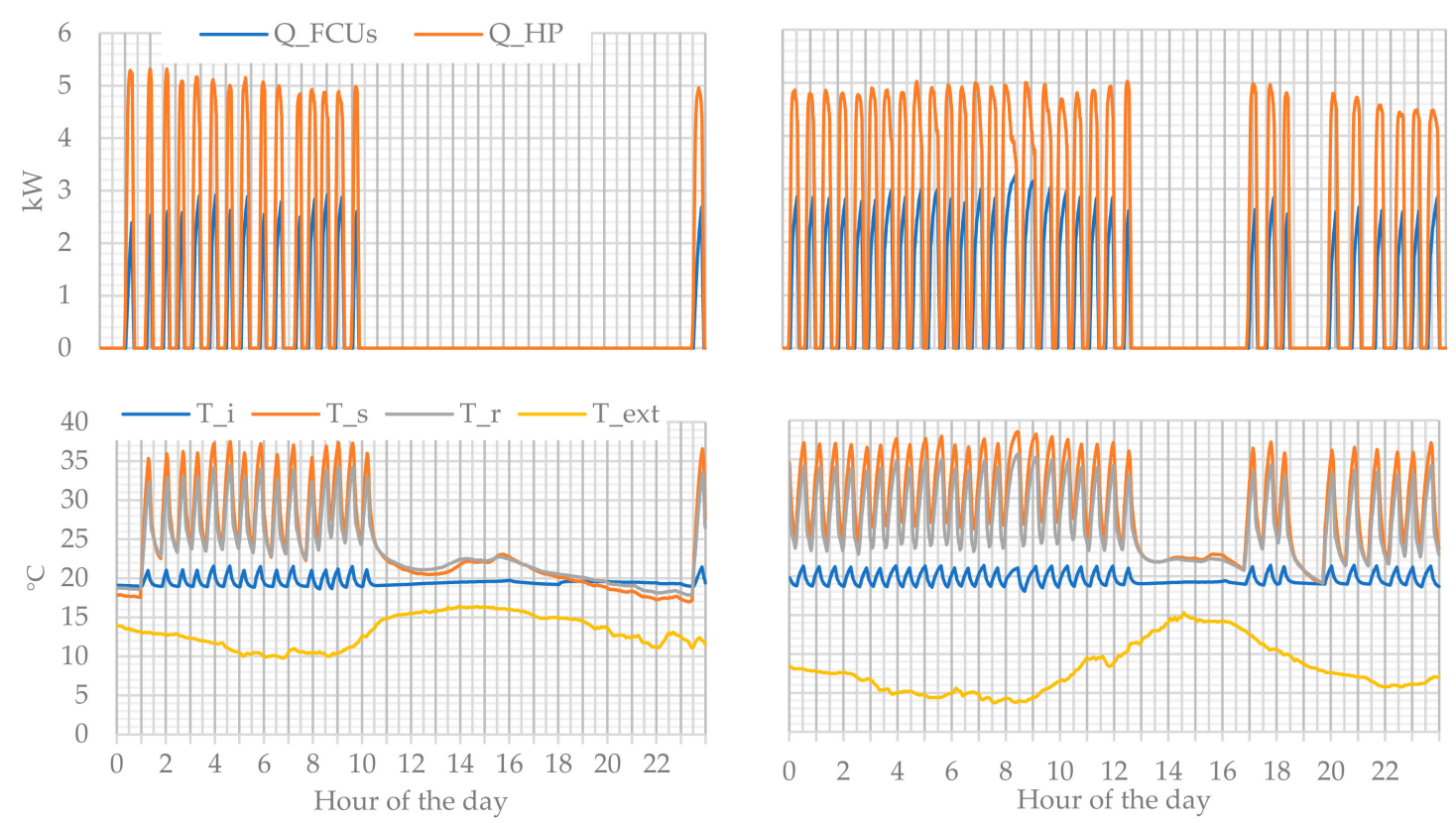

Figure 6. Typical mild (left) and cold (right) days under MOD\#1 (23-Dec., 5-Jan.).

Heat pump efficiency is affected by ON-OFF cycles: the experimental $S C O P_{A H P}$ under MOD\#1 is about $32 \%$ lower than the one evaluated according to manufacturer's datasheet (3.07 vs. 4.53$)$ at the same average outdoor temperature $\left(9^{\circ} \mathrm{C}\right)$, water supply temperature $\left(34^{\circ} \mathrm{C}\right)$, and integral-averaged capacity ratio (0.26), defined as the ratio of the thermal energy output and the maximum energy deliverable at nominal heating capacity. The deviation between the two performance indexes reflects the reduced accuracy of standardized methodologies and manufacturers' datasheets when the operational regime strongly fluctuates.

We also note that the generator has always provided a thermal power close to the nominal capacity (about $5 \mathrm{~kW}$ ) and almost twice the one exchanged by the FCUs (see Table 5 and Figure 11). The deviation between the two power profiles represents the internal energy variation in the heating loop that is increasing its temperature. This additional energy does not result in useful heat for the building and it will be lost during the following OFF period when the water loop cools down. The energy losses associated with the just-described behavior are quantified by $S C O P_{\text {sys }}$ which is about $35 \%$ lower than while $S C O P_{A H P}(2.00$ vs. 3.07$)$.

Finally, we note that the intermittent work regime occurred for both mild and cold outdoor temperatures (see Figure 5): a colder climate only increased the number of ON-OFF cycles as the FCU thermal output has been always greater than building heating demand. 


\subsection{Analysis of MOD\#2 Operational Strategy: Effects of Fan Coils' Speed}

MOD\#2 $\left(\mathrm{Vel}=\mathrm{LOW} ; \mathrm{T}_{s, A H P}^{*}=40^{\circ} \mathrm{C}\right)$ shows a little more regular operation than of MOD\#1 (see Figure 7), but the intermittent regime was maintained. The typical duration of ON periods almost doubles from 20 to $38 \mathrm{~min}$ (see Figure 9), but the number of ON-OFF cycles is still relevant for both cold and mild days. We note that the heating system reached a steady state condition in a few hours during night-time due to a reduced output of the heat emission system (see Table 5). The longer period required to reach the switching off condition (i.e., $21^{\circ} \mathrm{C}$ ) was sufficient for the heat pump to modulate its compressor.

However, the actual heat pump performance was 35\% lower than the one evaluated according to the manufacturer's datasheet $(2.95$ vs. 4.56$)$ at the same average outdoor temperature $\left(9{ }^{\circ} \mathrm{C}\right)$, water supply temperature $\left(36^{\circ} \mathrm{C}\right)$, and integral-averaged capacity ratio $(0.31)$. The deviation between $S C O P_{A H P}$ and $S C O P_{s y s}$ (i.e., 2.95 vs. 2.02) confirms the relevance of the thermal losses due to the continuous variation in water loop temperature and the low significance of manufacturers' datasheets in intermittent work regimes.
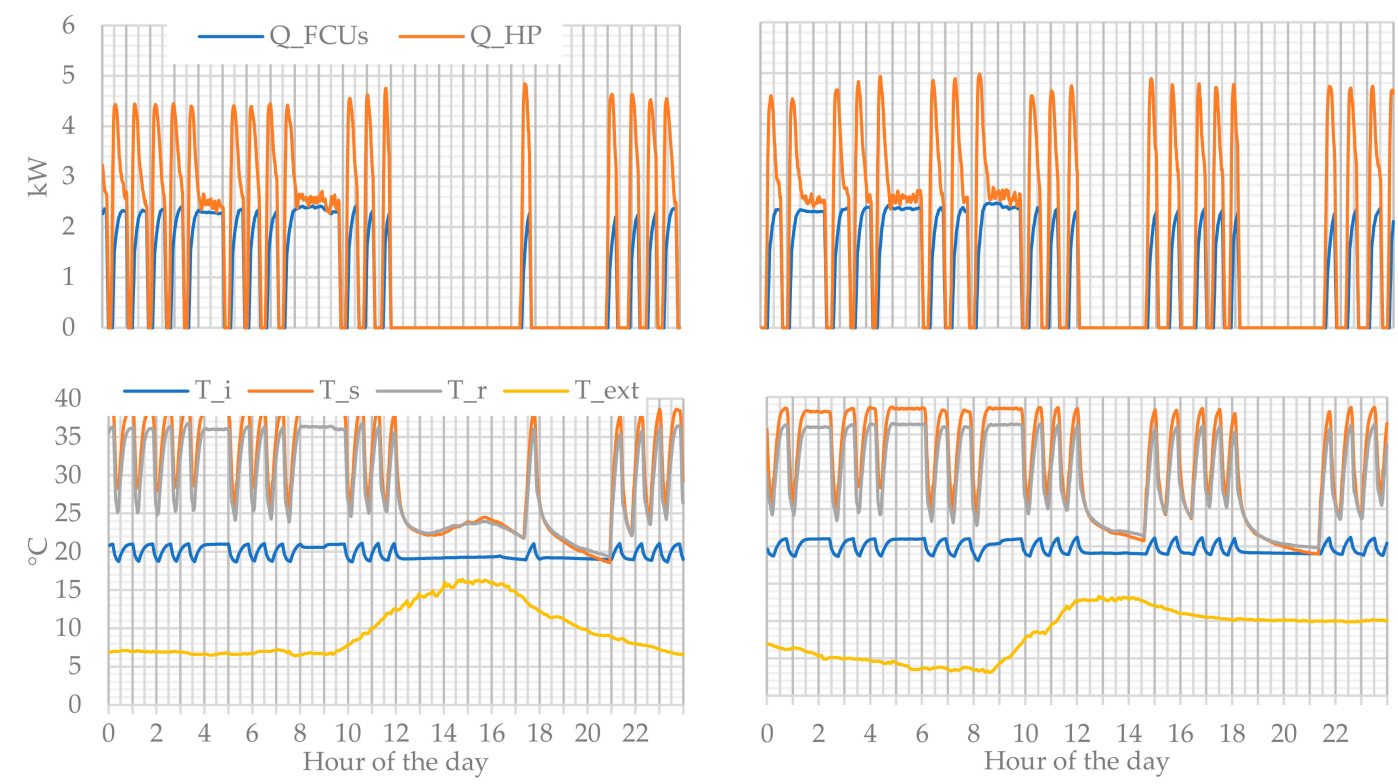

Figure 7. Typical mild (left) and cold (right) days under MOD\#2 (22-Jan., 19-Jan.).

\subsection{Analysis of MOD\#3 Operational Strategy: Effects of Supply Temperature}

MOD\#3 $\left(\mathrm{Vel}=\mathrm{LOW} ; \mathrm{T}_{s, A H P}^{*}=35^{\circ} \mathrm{C}\right)$ shows an improved behaviour of the system. The heat pump operation is characterized by a few constants ON periods, mainly occurring at night-time (see Figure 8). The average duration of ON periods under MOD\#3 is shown in Figure 10: we note long ON periods of some hours. The average AHP thermal output during ON periods decreases from $4.00 \mathrm{~kW}$ in MOD\#1 to $1.39 \mathrm{~kW}$ in MOD\#3, which is a more similar value to the FCU thermal output $(1.17 \mathrm{~kW})$. Shortly, under MOD\#3, the HVAC system reaches a steady state condition and a thermal balance with the building heating demand. The losses of the heating loop $(0.12 \mathrm{~kW})$ were reduced with respect to MOD\#1 $(0.55 \mathrm{~kW})$ and MOD\#2 $(0.59 \mathrm{~kW})$ due to the absence of the continuous alternation of additional heating-up requirements and deactivation losses. Under MOD\#3, the compressor has enough time to start modulating its speed, mainly working with a compressor frequency in the $20-30 \mathrm{~Hz}$ range (see Figure 9). These work conditions decrease the inefficiencies due to ON-OFF cycles; consequently, $S_{S C O P} A H P$ increases to 3.03 and $S C O P_{\text {sys }}$ increases to 2.56 . However, we note that the actual heat pump performance was $32 \%$ lower than the one evaluated according to manufacturer's datasheet (3.03 vs. 3.52$)$ at the same average outdoor temperature $\left(11^{\circ} \mathrm{C}\right)$, water supply temperature $\left(33^{\circ} \mathrm{C}\right)$, and integral-averaged capacity ratio (0.13). 

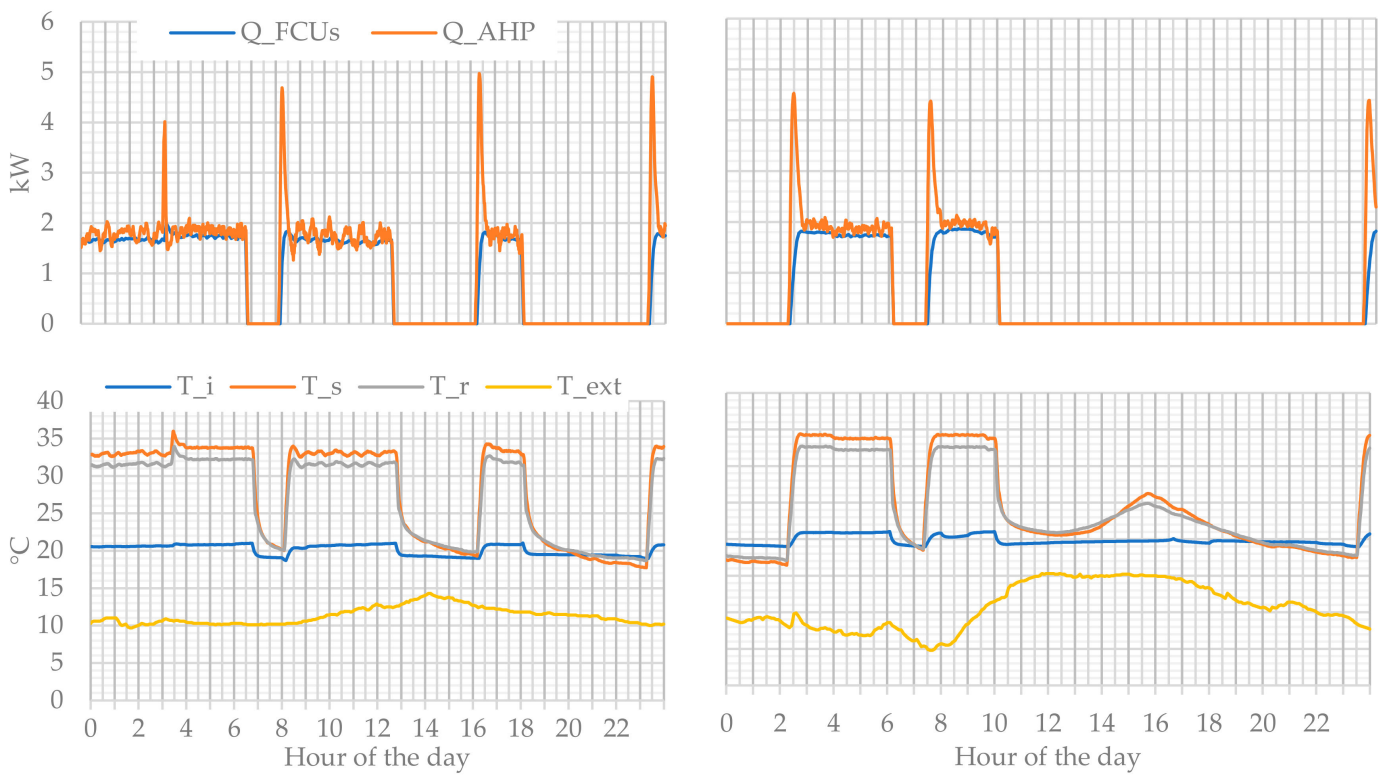

Figure 8. Typical mild (left) and colder (right) days under MOD\#3 (25-Jan., 5-Feb.).

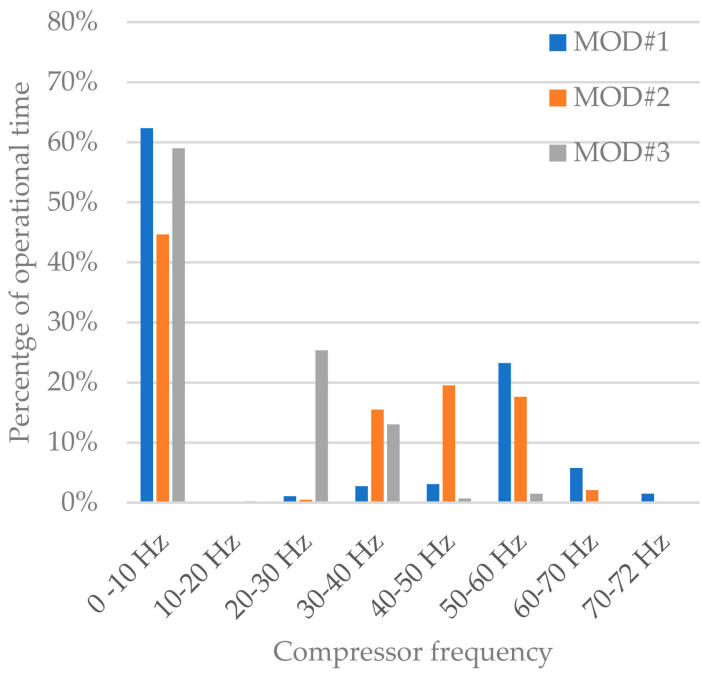

Figure 9. Compressor frequency distribution as percentage of time under each operational mode.

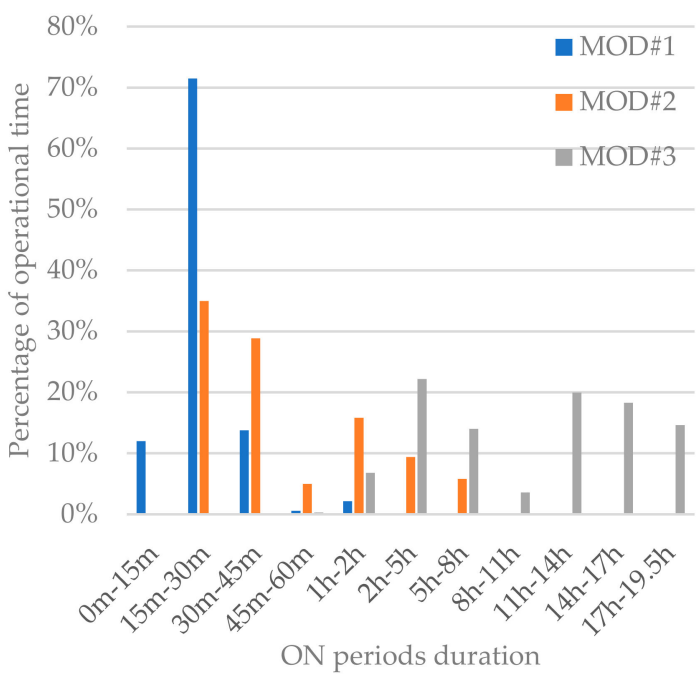

Figure 10. Distribution of the ON periods duration under each operational mode. 


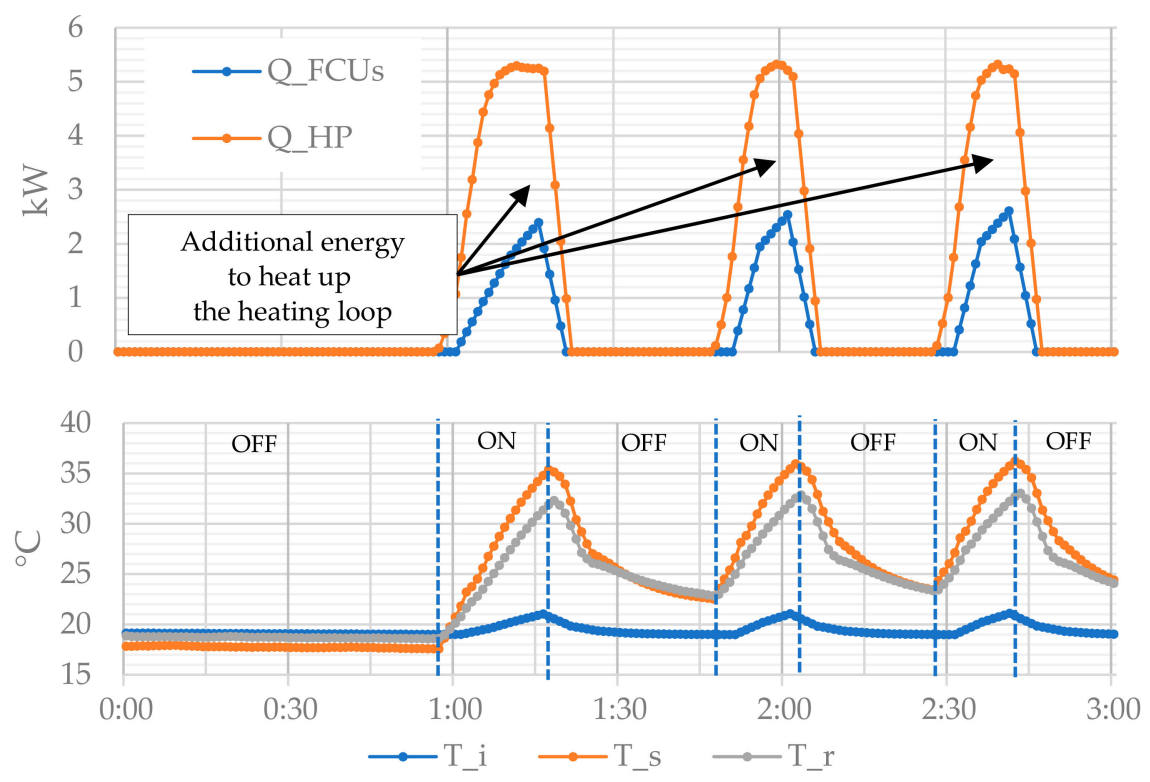

Figure 11. Detail of ON-OFF cycles under MOD\#1.

Table 5. Summary of AHP and Overall System Performances.

\begin{tabular}{|c|c|c|c|}
\hline & $\begin{array}{c}\text { MOD\#1 } \\
V e l=M E D \\
T_{s, A H P}^{*}=40{ }^{\circ} \mathrm{C}\end{array}$ & $\begin{array}{c}\text { MOD\#2 } \\
V e l=L O W \\
T_{s, A H P}^{*}=40^{\circ} \mathrm{C}\end{array}$ & $\begin{array}{c}\text { MOD\#3 } \\
V e l=L O W \\
T_{s, A H P}^{*}=35^{\circ} \mathrm{C}\end{array}$ \\
\hline$S C O P_{A H P}$ & 3.07 & 2.95 & 3.03 \\
\hline$S C O P_{s y s}$ & 2.00 & 2.02 & 2.56 \\
\hline Average heat pump output during ON periods- $k W$ & 4.14 & 3.34 & 1.39 \\
\hline Average fan coils output during ON periods-kW & 2.28 & 1.90 & 1.17 \\
\hline Average supply temperature during ON periods- ${ }^{\circ}$ & 33.7 & 35.6 & 33.0 \\
\hline Average outdoor temperature during $\mathrm{ON}$ periods $-{ }^{\circ} \mathrm{C}$ & 9.0 & 8.7 & 11.0 \\
\hline $\begin{array}{l}\text { Integral-averaged AHP capacity ratio } \\
\text { during ON periods }\end{array}$ & 0.69 & 0.57 & 0.22 \\
\hline $\begin{array}{l}\text { Integral-averaged AHP capacity ratioover the total } \\
\text { test period }\end{array}$ & 0.26 & 0.31 & 0.13 \\
\hline Integral-average losses over the total test period-kW & 0.55 & 0.59 & 12 \\
\hline $\begin{array}{l}S C O P_{A H P} \text { (according to manufacturer's datasheet } \\
\text { and reference technical standards) }\end{array}$ & 4.53. & 4.56 & 3.52 \\
\hline
\end{tabular}

In conclusion, for all the three control strategies, the experimental data showed a considerable reduction (30-45\%) of the coefficients of performance with respect to the ones based on manufacturer's datasheet and technical standards.

Moreover, in any MOD, the actual performances of the heat pump were about 3 . The latter value is lower than the expectations considering the mild climate of Pisa. With reference to the Italian residential energy market, we recall that the break-even seasonal performance required for an electrically driven heat pump to be economically advantageous with respect to a gas boiler is in the range 2.2-2.5, depending on actual prices of natural gas, electricity, and boiler efficiency.

\section{Conclusions}

This paper presents the results the HiL extensive experimental campaign performed at BE-IES laboratory of DESTEC (University of Pisa). We measured the actual performance of an air heat pump system used in a typical residential building, during the winter season, according to three different operational modes. We also compared the experimental performances with the corresponding ones evaluated through the state-of-the-art methodology presented in current technical standards (i.e., [22,24]). The emulated building consists of an apartment located at the top floor of a multi-apartment 
building in Pisa. The simulation/emulation periods went from November 2019 till February 2020: about $740 \mathrm{~h}$ of data were collected every minute. The results pointed out three main findings:

- The typical thermal design load results in an overestimated value of FCU capacity and the thermal zone thermostats continuously sent an ON-OFF signal to the heat generator. The heating system never reached a steady state condition under MOD\#1, with notable losses due to the continuous heating-up and cool-down phases occurring twice per hour. The reduction in supply temperature from 40 to $35^{\circ} \mathrm{C}$ has been the key to ensure smoother operations. The average duration of the ON periods increased from $20 \mathrm{~min}$ in MOD\#1 to about $10 \mathrm{~h}$ in MOD\#3. The fan speed reduction resulted in a less effective strategy to reduce the ON-OFF cycles;

- The experimental performance of the AHP device in MOD\#1 and MOD\#2, SCOP AHP, was about $35 \%$ lower than the one evaluated through current state-of-the-art methodologies, based on manufacturer's datasheet and empirical correlations for accounting partial-load conditions (3.07 vs. 4.53 and 2.95 vs. 4.56 ). The deviation between experimental and simulated results reduced to $14 \%$ when the system operated in smoother regimes, namely in MOD\#3 (3.03 vs. 3.52). The actual $S C O P_{A H P}$ value was about 3 and this is quite above the threshold value for an electrically driven heat pump to be convenient with respect to a gas boiler (minimum SCOP about 2.2-2.5);

- The performance of the overall building-HVAC system is notably reduced by the transient regime of the heating system. $S C O P_{s y s}$ is about $50 \%$ of $S C O P_{A H P}$ in MOD\#1 and MOD\#2 and about $16 \%$ in MOD\#3. At the end, the seasonal performance of the overall HVAC-building system, $S_{C O P}$ sys, $_{\text {, }}$ was equal to 2.00, 2.02, 2.56 which is lower than the values expected in a mild climate such as the one of Pisa. The main losses are associated with the continuous heating-up and deactivation sequences: the delivered energy to heat up the water after an off period was lost at the next off period. In such conditions, the thermal losses of the water loop are relevant with respect to the heat provided by the AHP (32\% in MOD\#1 and MOD\#2 and 15\% in MOD\#3).

The analysis here presented demonstrates the potential of the HiL approach to properly estimate energy consumptions of and available improvements to HVAC systems under real operative conditions. The utilization of standardized methodologies, even if based on manufacturers' datasheets, can lead to significative deviations from actual performances due to the difficulty of capturing the transient performances of the devices and the interaction between building and HVAC dynamics.

The HiL approach is also promising for developing advanced operational strategies. In the presented case study, the use of a weather-base control for the supply temperature is expected to be advantageous. The use of a thermal storage can be beneficial as well: it can be used to store heat during the hottest hours of the day, when the building does not require heating and the outdoor temperatures are favorable. Additionally, ON-OFF losses will be reduced as the heat pump will experience a constant operation during the "charging" phases of the storage. In other words, the stored heat will be delivered to the building with a peak-shaving effect. The latter improvement can also be achieved with smaller storage volumes and will be the goal of another experimental campaign at the BE-IES laboratory.

Author Contributions: Conceptualization, C.B., P.C., A.F. and D.T.; methodology, C.B., P.C., A.F. and D.T.; software, P.C.; formal analysis, C.B., P.C., A.F. and D.T.; data curation, P.C.; writing-Original draft preparation, P.C.; writing-Review and editing, C.B., P.C., A.F. and D.T. All authors have read and agreed to the published version of the manuscript.

Funding: The authors gratefully acknowledge the financial support of the Italian Ministry of Education, University and Research (MIUR), in the framework of the Research Project of Relevant National Interest (PRIN) "The energy FLEXibility of enhanced HEAT pumps for the next generation of sustainable buildings (FLEXHEAT)" (PRIN 2017, Sector PE8, Line A, Grant n. 33).

Acknowledgments: We acknowledge the other colleagues, technical staff and students of DESTEC department of the University of Pisa, who contributed to the development of the BE-IES laboratory and to the experimental campaign, with special thanks to Davide Della Vista, Roberto Manetti, Riccardo Dinelli, Alessandro Conforti, and Niccolò Malfanti.

Conflicts of Interest: The authors declare no conflict of interest. 


\section{Nomenclature}

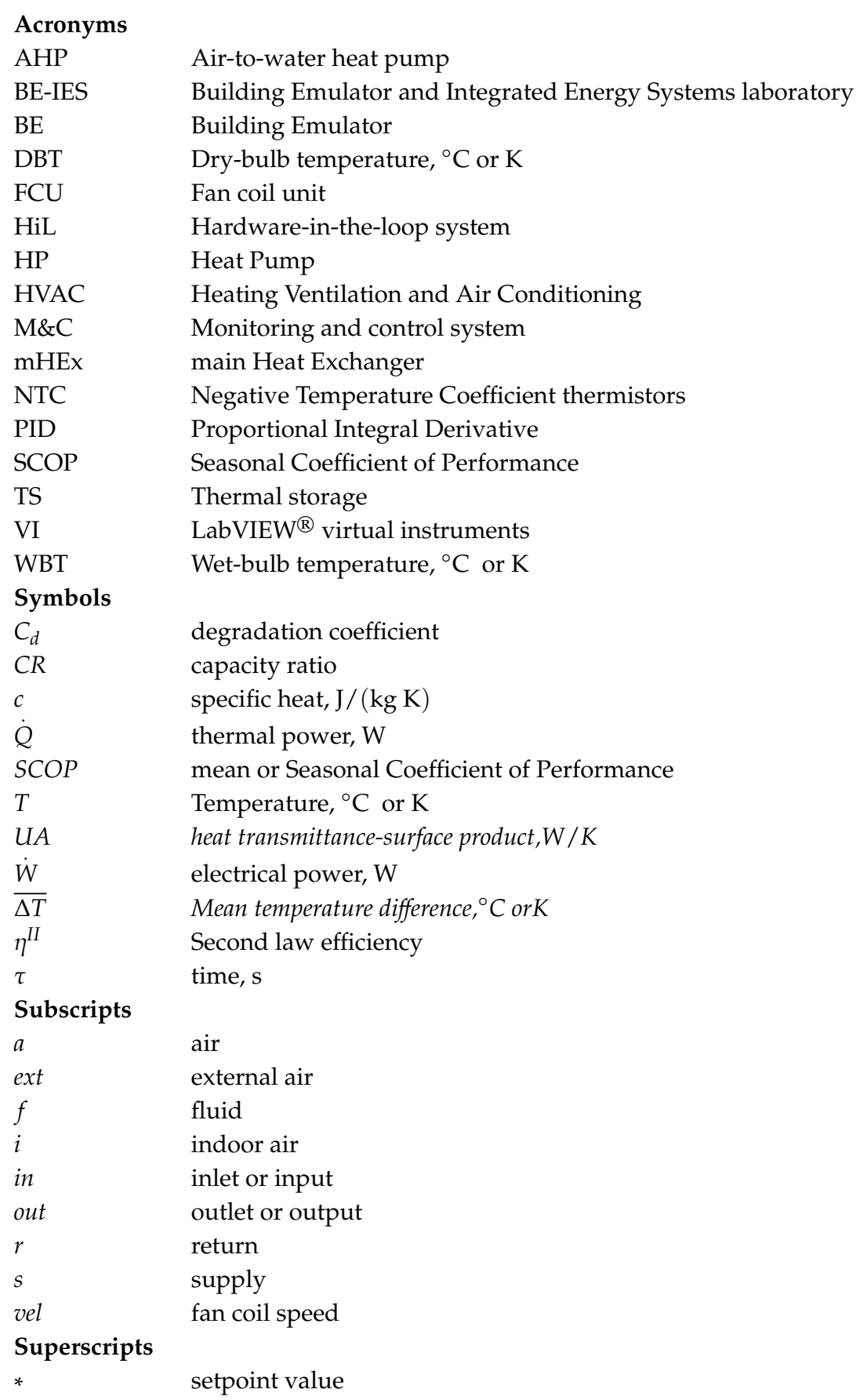

\section{Appendix A. AHP Manufacturer's Datasheet and State-Of-The-Art Methodology Based on Second-Law Efficiency}

The most common methodology at both a professional and research level to assess the heat pump performances is based on the interpolation of the so-called second-law or exergy efficiency, $\eta^{I I}$. The procedure is based on the manufacturers' experimental data provided in accordance with EN 14511-2:2018 and EN 14825:2018 (see, for example, Table A1). The data on these datasheets are generally marked with the subscript $D C$ that indicates a quantity evaluated at maximum compressor speed. The second-law efficiency $\eta_{D C}^{I I}$ is defined as in Equation (A1) and it is calculated for each $C O P_{D C}$ value provided by the manufacturer

$$
\eta_{D C}^{I I}=C O P_{D C} \frac{T_{o u t, H P, D C}-T_{a, i n, H P, D C}}{T_{o u t, H P, D C}+273.15}
$$


Then, $\eta_{D C}^{I I}$ is interpolated according to the actual supply and outdoor temperature $T_{\text {out }, H P}$ and $T_{a, i n, H P}$. We refer to the result of the interpolation procedure as $\eta^{I I}$. Similarly, the maximum power output of the device at the actual temperature conditions, $\dot{Q}_{\max }\left(T_{\text {out }, H P} ; T_{a, i n, H P}\right)$, is evaluated through interpolation of $\dot{Q}_{\text {out }, D C}$. The capacity ratio of the device is evaluated according to the average actual thermal output, $\dot{Q}$, over the considered time (off periods included), namely

$$
C R=\frac{\dot{Q}_{\text {out }}}{\dot{Q}_{\max }\left(T_{\text {out }, H P} ; T_{a, \text { in }, H P}\right)}
$$

According to the above-mentioned technical standards, it is possible to evaluate a penalization factor, $f_{C R}$, as a function of $C R$ and its capacity control system. For variable capacity units, Equation (A3) applies

$$
f_{C R}(C R)=f(x)=\left\{\begin{aligned}
1, & C R \geq C R_{\text {min }} \\
\frac{C R}{C R \times C_{d}+\left(1-C_{d}\right)}, & C R<C R_{\text {min }}
\end{aligned}\right.
$$

The degradation coefficient $C_{d}$ and the minimum control level, $C R_{\min }$, can be provided by the manufacturer or read in EN 14825:2018. Finally, the actual COP and energy input is evaluated as

$$
\begin{gathered}
C O P\left(T_{\text {out }, H P} ; T_{a, i n, H P} ; C R\right)=\frac{T_{\text {out }, H P}+273.15}{T_{\text {out }, H P}-T_{a, i n, H P}} \times \eta^{I I}\left(T_{\text {out }, H P} ; T_{a, \text { in }, H P}\right) \times f_{C R}(C R) \\
\dot{W}_{\text {in }}=\frac{\dot{Q}_{\text {out }}}{\operatorname{COP}\left(T_{\text {out }, H P} ; T_{a, \text { in }, H P} ; C R\right)}
\end{gathered}
$$

\begin{tabular}{|c|c|c|c|c|c|c|c|c|c|c|c|c|c|c|}
\hline \multirow{2}{*}{$\frac{T_{o u t, H P}{ }^{\circ} \mathrm{C}}{T_{a, i n}{ }^{\circ} \mathrm{C}}$} & \multicolumn{2}{|c|}{25} & \multicolumn{2}{|c|}{30} & \multicolumn{2}{|c|}{35} & \multicolumn{2}{|c|}{40} & \multicolumn{2}{|c|}{45} & \multicolumn{2}{|c|}{50} & \multicolumn{2}{|c|}{55} \\
\hline & $\begin{array}{l}\dot{Q}_{\text {out }, D C} \\
{[\mathbf{k W}]}\end{array}$ & $\begin{array}{c}\dot{W}_{i n} \\
{[\mathbf{k W}]}\end{array}$ & $\begin{array}{c}\dot{Q}_{\text {out } t, D C} \\
{[\mathbf{k W}]}\end{array}$ & $\begin{array}{c}\dot{W}_{i n, D C} \\
{[\mathbf{k W}]}\end{array}$ & $\begin{array}{c}\dot{Q}_{\text {out }, D C} \\
{[\mathbf{k W}]}\end{array}$ & $\begin{array}{c}\dot{W}_{i n, D C} \\
{[\mathbf{k W}]}\end{array}$ & $\begin{array}{c}\dot{Q}_{\text {out }, D C} \\
{[\mathbf{k W}]}\end{array}$ & $\begin{array}{c}\dot{W}_{i n, D C} \\
{[\mathbf{k W}]}\end{array}$ & $\begin{array}{c}\dot{Q}_{\text {out }, D C} \\
{[\mathbf{k W}]}\end{array}$ & $\begin{array}{c}\dot{W}_{i n, D C} \\
{[\mathbf{k W}]}\end{array}$ & $\begin{array}{c}\dot{Q}_{\text {out }, D C} \\
{[\mathbf{k W}]}\end{array}$ & $\begin{array}{c}\dot{W}_{i n, D C} \\
{[\mathbf{k W}]}\end{array}$ & $\begin{array}{c}\dot{Q}_{\text {out }, D C} \\
{[\mathbf{k W}]}\end{array}$ & $\begin{array}{c}\dot{W}_{i n, D C} \\
{[\mathbf{k W}]}\end{array}$ \\
\hline-20 & 5.24 & 1.83 & 5.01 & 2.07 & 4.78 & 2.3 & 4.55 & 2.54 & - & - & - & - & - & - \\
\hline-10 & 5.96 & 1.8 & 5.8 & 2.04 & 5.51 & 2.27 & 5.49 & 2.5 & 5.33 & 2.73 & 5.17 & 2.96 & 5.01 & 3.19 \\
\hline-7 & 6.14 & 1.79 & 6.02 & 2.02 & 5.91 & 2.25 & 5.79 & 2.47 & 5.67 & 2.7 & 5.56 & 2.93 & 5.44 & 3.16 \\
\hline-2 & 6.44 & 1.56 & 6.31 & 1.77 & 6.18 & 1.98 & 6.06 & 2.19 & 5.93 & 2.4 & 5.8 & 2.6 & 5.67 & 2.81 \\
\hline 2 & 6.51 & 1.29 & 6.37 & 1.48 & 6.24 & 1.66 & 6.1 & 1.85 & 5.97 & 2.03 & 5.83 & 2.22 & 5.7 & 2.4 \\
\hline 15 & 6.79 & 1.07 & 6.57 & 1.2 & 6.35 & 1.34 & 6.13 & 1.47 & 5.92 & 1.61 & 5.7 & 1.74 & 5.48 & 1.88 \\
\hline 20 & 7.1 & 1.1 & 6.9 & 1.24 & 6.7 & 1.37 & 6.5 & 1.51 & 6.3 & 1.64 & 6.1 & 1.78 & 5.9 & 1.91 \\
\hline
\end{tabular}

The procedure is generally applied on an hourly or monthly time step.

Table A1. Manufacturer's Datasheet of the Considered Air-to-Water Heat Pump ${ }^{1}$. Grey Boxes Refer to Nominal Data.

${ }^{1}$ Rating conditions in accordance with EN 14511-2:2018. Heating capacity is according to Eurovent rating standard RS-6/C/001-2011 and valid for heated water range $\Delta T=3 \sim 8{ }^{\circ} \mathrm{C}$.

\section{References}

1. Fischer, D.; Madani, H. On heat pumps in smart grids: A review. Renew. Sustain. Energy Rev. 2017, 70, 342-357. [CrossRef]

2. Franco, A.; Salza, P. Strategies for optimal penetration of intermittent renewables in complex energy systems based on techno-operational objectives. Renew. Energy 2011, 36, 743-753. [CrossRef]

3. Testi, D.; Urbanucci, L.; Giola, C.; Schito, E.; Conti, P. Stochastic optimal integration of decentralized heat pumps in a smart thermal and electric micro-grid. Energy Convers. Manag. 2020, 210, 112734. [CrossRef]

4. Conti, P.; Lutzemberger, G.; Schito, E.; Poli, D.; Testi, D. Multi-Objective Optimization of Off-Grid Hybrid Renewable Energy Systems in Buildings with Prior Design-Variable Screening. Energies 2019, $12,3026$. [CrossRef]

5. Testi, D.; Conti, P.; Schito, E.; Urbanucci, L.; D’Ettorre, F. Synthesis and Optimal Operation of Smart Microgrids Serving a Cluster of Buildings on a Campus with Centralized and Distributed Hybrid Renewable Energy Units. Energies 2019, 12, 745. [CrossRef]

6. Péan, T.Q.; Salom, J.; Costa-Castelló, R. Review of control strategies for improving the energy flexibility provided by heat pump systems in buildings. J. Process Control 2019, 74, 35-49. [CrossRef] 
7. D'Ettorre, F.; Conti, P.; Schito, E.; Testi, D. Model predictive control of a hybrid heat pump system and impact of the prediction horizon on cost-saving potential and optimal storage capacity. Appl. Therm. Eng. 2019, 148, 524-535. [CrossRef]

8. D'Ettorre, F.; de Rosa, M.; Conti, P.; Testi, D.; Finn, D. Mapping the energy flexibility potential of single buildings equipped with optimally-controlled heat pump, gas boilers and thermal storage. Sustain. Cities Soc. 2019, 50, 101689. [CrossRef]

9. Fischer, D.; Wirtz, T.; Zerbe, K.D.; Wille-Haussmann, B.; Madani, H. Test cases for hardware in the loop testing of air to water heat pump systems in a smart grid context. In Proceedings of the International Congress of Refrigeration (ICR), Yokohama, Japan, 16-22 August 2015; pp. 3666-3673.

10. Mehrfeld, P.; Nürenberg, M.; Knorr, M.; Schinke, L.; Beyer, M.; Grimm, M.; Lauster, M.; Müller, D.; Seifert, J.; Stergiaropoulos, K. Dynamic evaluations of heat pump and micro combined heat and power systems using the hardware-in-the-loop approach. J. Build. Eng. 2020, 28, 101032. [CrossRef]

11. Franco, A.; Fantozzi, F. Experimental analysis of a self consumption strategy for residential building: The integration of PV system and geothermal heat pump. Renew. Energy 2016, 86, 1075-1085. [CrossRef]

12. Beck, T.; Kondziella, H.; Huard, G.; Bruckner, T. Optimal operation, configuration and sizing of generation and storage technologies for residential heat pump systems in the spotlight of self-consumption of photovoltaic electricity. Appl. Energy 2017, 188, 604-619. [CrossRef]

13. El-Baz, W.; Mayerhofer, L.; Tzscheutschler, P.; Wagner, U. Hardware in the loop real-time simulation for heating systems: Model validation and dynamics analysis. Energies 2018, 11, 3159. [CrossRef]

14. Frison, L.; Kleinstück, M.; Engelmann, P. Model-predictive control for testing energy flexible heat pump operation within a Hardware-in-the-Loop setting. J. Phys. Conf. Ser. 2019, 1343, 012068. [CrossRef]

15. Schneider, G.F.; Oppermann, J.; Constantin, A.; Streblow, R.; Müller, D. Hardware-in-the-Loop-Simulation of a Building Energy and Control System to Investigate Circulating Pump Control Using Modelica. In Proceedings of the 11th International Modelica Conference, Versailles, France, 21-23 September 2015; Volume 118, pp. 225-233.

16. Hallerbach, S.; Xia, Y.; Eberle, U.; Koester, F. Simulation-Based Identification of Critical Scenarios for Cooperative and Automated Vehicles. SAE Int. J. Connect. Autom. Veh. 2018, 1, 1066. [CrossRef]

17. Tejeda de la Cruz, A.; Riviere, P.; Marchio, D.; Cauret, O.; Milu, A. Hardware in the loop test bench using Modelica: A platform to test and improve the control of heating systems. Appl. Energy 2017, 188, 107-120. [CrossRef]

18. Bianchi, M.; Shafai, E.; Federal, S.; Geering, H.P. Comparing New Control Concepts for Heat Pump Heating Systems on a Test Bench With the Capability of House and Earth Probe Emulation. In Proceedings of the 8th International Energy Agency Heat Pump Conference, Las Vegas, NV, USA, 30 May-2 June 2005; pp. 1-11.

19. Stutterecker, W.; Schoberer, T.; Steindl, G. Development of a Hardware-in-the-Loop Test Method for Heat Pumps and Chillers. In Proceedings of the REHVA Annual Conference "Advanced HVAC and Natural Gas Technologies", Riga, Latvia, 6-9 May 2015; Riga Technical University: Riga, Latvia, 2015; p. 117.

20. Pratt, A.; Ruth, M.; Krishnamurthy, D.; Sparn, B.; Lunacek, M.; Jones, W.; Mittal, S.; Wu, H.; Marks, J. Hardware-in-the-loop simulation of a distribution system with air conditioners under model predictive control. IEEE Power Energy Soc. Gen. Meet. 2018, 2018, 1-5.

21. Rhee, K.N.; Yeo, M.S.; Kim, K.W. Evaluation of the control performance of hydronic radiant heating systems based on the emulation using hardware-in-the-loop simulation. Build. Environ. 2011, 46, 2012-2022. [CrossRef]

22. EN 15316-4-2. Heating Systems in Buildings-Method for Calculation of System Energy Requirements and System Efficiencies-Part 4-2: Space Heating Generation Systems, Heat Pump Systems; European Committee for Standardization (CEN): Brussels, Belgium, 2017.

23. EN 14511-2. Air Conditioners, Liquid Chilling Packages and Heat Pumps for Space Heating and Cooling and Process Chillers, with Electrically Driven compressors_Part 2: Test Conditions; European Committee for Standardization (CEN): Brussels, Belgium, 2018.

24. EN 14825. Air Conditioners, Liquid Chilling Packages and Heat Pumps, with Electrically Driven Compressors, for Space Heating and Cooling. Testing and Rating at Part Load Conditions and Calculation of Seasonal Performance; European Committee for Standardization (CEN): Brussels, Belgium, 2018. 
25. EN 52016-1. Energy Performance of Buildings-Energy Needs for Heating and Cooling, Internal Temperatures and Sensible and Latent Heat Loads_Part 1: Calculation Procedures; European Committee for Standardization (CEN): Brussels, Belgium, 2017.

26. Schito, E.; Conti, P.; Urbanucci, L.; Testi, D. Multi-objective optimization of HVAC control in museum environment for artwork preservation, visitors' thermal comfort and energy efficiency. Build. Environ. 2020, 180, 107018. [CrossRef]

27. EN 15316-1. Energy Performance of Buildings-Method for Calculation of System Energy Requirements and System Efficiences-Part 1: General and Energy Performance Expression; European Committee for Standardization (CEN): Brussels, Belgium, 2017.

28. EN 1397. Heat Exchangers-Hydronic Room Fan Coil Units-Test Procedures for Establishing the Performance; European Committee for Standardization (CEN): Brussels, Belgium, 2015.

29. Guoyuan, M.; Qinhu, C.; Yi, J. Experimental investigation of air-source heat pump for cold regions. Int. J. Refrig. 2003, 26, 12-18. [CrossRef]

30. Madonna, F.; Bazzocchi, F. Annual performances of reversible air-to-water heat pumps in small residential buildings. Energy Build. 2013, 65, 299-309. [CrossRef]

31. Testi, D.; Schito, E.; Tiberi, E.; Conti, P.; Grassi, W. Building Energy Simulation by an In-house Full Transient Model for Radiant Systems Coupled to a Modulating Heat Pump. Energy Procedia 2015, 78, 1135-1140. [CrossRef]

32. Dongellini, M.; Morini, G.L. On-off cycling losses of reversible air-to-water heat pump systems as a function of the unit power modulation capacity. Energy Convers. Manag. 2019, 196, 966-978. [CrossRef]

33. Tassou, S.A.; Votsis, P. Transient response and cycling losses of air-to-water heat pump systems. Heat Recover. Syst. CHP 1992, 12, 123-129. [CrossRef]

34. Bagarella, G.; Lazzarin, R.M.; Lamanna, B. Cycling losses in refrigeration equipment: An experimental evaluation. Int. J. Refrig. 2013, 36, 2111-2118. [CrossRef]

35. Piechurski, K.; Szulgowska-Zgrzywa, M.; Danielewicz, J. The impact of the work under partial load on the energy efficiency of an air-to-water heat pump. E3S Web Conf. 2017, 17, 00072. [CrossRef]

(C) 2020 by the authors. Licensee MDPI, Basel, Switzerland. This article is an open access article distributed under the terms and conditions of the Creative Commons Attribution (CC BY) license (http://creativecommons.org/licenses/by/4.0/). 